\title{
The Biology of Prolotherapy and Its Application in Clinical Cervical Spine Instability and Chronic Neck Pain: A Retrospective Study
}

\author{
Ross A. Hauser ${ }^{1}$, Danielle Steilen ${ }^{1}$, Karina Gordin ${ }^{2, ~ *}$ \\ ${ }^{1}$ Caring Medical \& Rehabilitation Services, Oak Park, IL, USA \\ ${ }^{2}$ HealthWright, Wayland, MA, USA
}

Email address:

Write@HealthWright.org (K. Gordin)

\section{To cite this article:}

Ross A. Hauser, Danielle Steilen, Karina Gordin. The Biology of Prolotherapy and Its Application in Clinical Cervical Spine Instability and Chronic Neck Pain: A Retrospective Study. European Journal of Preventive Medicine. Vol. 3, No. 4, 2015, pp. 85-102.

doi: $10.11648 /$ j.ejpm.20150304.11

\begin{abstract}
Background: In an effort to facilitate the diagnosis and treatment of clinical cervical spine instability (CCSI) and chronic neck pain, we investigated the role of proliferative injection Prolotherapy in the reduction of pain and recovery of constitutional and neurological symptoms associated with increased intervertebral motion, structural deformity and irritation of nerve roots. Methods: For this retrospective case series, 21 study participants were selected from patients seen for the primary complaint of cervicalgia. Following a series of proliferative injections, performed in a private sub-specialty pain clinic, patientreported assessments were measured using questionnaire data, including range of motion (ROM), crunching, stiffness, pain level, numbness, and exercise ability, between 1 and 39 months post-treatment (mean $=24$ months). All patients signed a consent form prior to treatment. Results: 95 percent of patients reported that Prolotherapy met their expectations in regards to pain relief and functionality. Significant reductions in pain at rest, during normal activity, and during exercise were reported. A mean of 86 percent of patients reported overall sustained improvement, while 33 percent reported complete functional recovery. 31 percent of patients reported complete relief of all recorded symptoms. No adverse events were reported. Conclusion: The results of this study demonstrate statistically significant reductions in pain and functionality, indicating the safety and viability of Prolotherapy for cervical spine instability. Such clinical efficacy of this procedure warrants further investigation as a noninvasive treatment option.
\end{abstract}

Keywords: Atlanto-Axial Joint, Barré-Liéou Syndrome, Cervicalgia, Cervical Instability, Facet Joint Injury, Manual Therapy, Posterior Cervical Sympathetic Syndrome, Prolotherapy

\section{Introduction}

Cervical spine (C-spine) injuries may be serious due to the region's unique anatomic and biomechanical mechanisms. As such, high functional demands placed on vertebral motion segments can render them vulnerable to injuries that can range in severity from soft tissue contusions to neurogenic and sensory disturbances following osteo-ligamentous trauma. Similarly, the etiology of C-spinal complaints is variable since a range of inflammatory diseases, as well as degenerative, iatrogenic and connective tissue disorders affecting bones, joints, disks and ligamentous support structures can produce C-spine instability. Such clinical manifestations may be further confounded by their poorly detectable nature, identified incidentally in connective tissue disorders associated with ligament laxity and congenital anomalies. All these factors contribute to the challenges healthcare professionals encounter with increasing frequency when trying to determine clinical presentations, including pre-existing (congenital or acquired) cervical spinal dysfunctions, and autonomic deficits relating to clinical cervical spinal instability (CCSI). A. A. White [1] defined clinical spine instability as the vertebral column's loss of ability to support physiological loads in order to maintain the relationship between vertebrae, as well as to prevent nerve root damage or irritation. Clinically, the term "spinal stability" has adopted the definition of the spine's ability to maintain alignment as well as provide protection to the neural network 
it encloses during physiologic loading [2]. Manifestations of instability include loss of stiffness, disk height reduction, ligament and facet capsule laxity, as well as degeneration of facet joints. Such progressive degenerative mechanisms of dysfunction and re-stabilization result in increased and aberrant range of motion [3].

Considering CCSI is not an exclusive disease but a pathological result of a combination of traumatic injuries and degenerative conditions characterized by distinct epidemiology, determining the incidence and prevalence in the general population is challenging. In regards to age, the frequency of injuries to the cervical spine peaks at ages 15 to 35 and greater than 65 years [4], and generally occurs in 1.5 percent to 3 percent of all major trauma cases [5]. In the general population, the incidence of neck pain in a single year is estimated to range between 10.4 percent and 21.3 percent, with a greater incidence observed in office and computer workers. Additionally, while 33 percent to 65 percent of people recover from episodic neck pain at 1 year, most cases run over a lifetime, and as such, relapses are common [6].

The most common etiology of neck injury includes motor vehicle accidents (50 percent to 70 percent), with estimates indicating more than 1 million whiplash injuries occurring annually; in fact, Barnsley et al [7] estimated that the annual incidence of whiplash related symptoms is 3.8 cases per 1000 population. Freeman et al [8] suggested that 6.2 percent of the US population (15.5 million people) suffers from late whiplash syndrome - a condition characterized by progressive pain, joint stiffness, post-injury laxity and instability [9] associated with trauma from whiplash-like loads of combined shear, bending and compression forces [10] generated during sudden acceleration-deceleration. Depending on the load application vector, comparable damage is typically sustained by the anterior longitudinal ligament (ALL), facet capsular (FC) ligaments and ligamentum flavum (LF) [ 11] following cervical hyperextension and/or hyperflexion [ 12 ], respectively, placing the ligaments at risk of laxity. Under normal circumstances, these ligaments afford substantial stability; however, investigators have postulated that hyper-straining affects the tissue's ability to limit motion. This may lead to supra-physiologic range of motion (ROM), subsequent nervous tissue impingement and injuries to adjacent perispinous soft tissue $[13,14]$, ultimately precipitating cervical spinal instability and involvement of the cervical sympathetic system.

Aside from vehicular accidents and whiplash related symptoms, leisure-time activities and other risk factors increase the incidence of $\mathrm{C}$-spine instability, including falls (6 percent to 10 percent); blunt head and neck traumas; assaults; diving accidents; penetrating (i.e. ballistic) neck injuries and contact sport events. Such mid to high-velocity impact and forced flexion-extension or axial compression, induced by loads beyond the tolerance threshold of cervical ligaments and bones, may result in sub-failure mechanism responses. If not properly diagnosed and managed, any additional chronic repetitive non-catastrophic trauma can precipitate diffuse symptoms, which present as dysfunctioning collagen fibers and neural cells send deficit information to spinal muscles, generating disproportionate responses and symptoms like migraines, dizziness, nausea, and more commonly- chronic neck pain.

\subsection{Stabilizing Features of the Cervical Spine: Anatomy and Function}

The cervical spine is typically separated into two distinct functional and structural divisions: the upper cervical $(\mathrm{C} 0-\mathrm{C} 2)$ and lower cervical (C3-C7). The former is distinguished by the many muscle and ligament attachments, lack of intervertebral disk between $\mathrm{C} 1$ and $\mathrm{C} 2$, and distinctly structured bones and surfaces. A lower cervical vertebra typically is characterized by a vertebral body, intervertebral disk, and both a right and left superior and inferior articular facet, which hinges the vertebrae together. These articular facets make up the cervical facet joints, located at the back of the spine, and are each surrounded by a thin ligamentous capsule connective tissue in which hyaline cartilage coats articular surfaces while synovial fluid nourishes and lubricates. The spinal nerve exiting through the intervertebral foramen is closely related to the facet and uncovertebral joint, and intervertebral disk, so pathology affecting any one or a combination of these structures may lead to nerve root irritation or compromise [15]. Abnormal joint movement related to ligamentous laxity may generate a variety of protective actions by adjacent tissue, such as muscle contracting/spasming in an attempt to stabilize or protect the joints from further trauma.

The upper cervical spine $(\mathrm{C} 0-\mathrm{C} 2)$ is the most mobile section of the vertebral column and as such the region is particularly vulnerable to non-penetrating acceleration trauma. Horizontally oriented facet joints, located between the atlas and axis, allow for 50 percent of total neck rotation, though their fibrous capsular ligaments may be affected by accentuated axial rotation during impact [16]. When the head is initially flexed and rotated, the ligaments are susceptible to forces of impact and rotational components of rear-end motor vehicle accidents. Alar ligaments are particularly sensitive to such mechanisms considering they chiefly consist of collagenous fibers and few elastic fibers [17] which can be stretched only 10 to 20 percent of the original length before damage or rupture occurs [18]. If one alar ligament is injured, the chief mechanism of motion restriction (axial rotation) is no longer limited.

Discussing the stabilizing features of the cervical spine, particularly in the context of their response to aberrant motion and injury, might be helpful in considering the unique anatomy and broad function of the region. In the whiplash scenario, if the head is turned or rotated, the cervical muscles, facets, ligaments, and annulus of the disc are tightened, predisposing the facet joint capsule to strain, and severe overstretching or even rupture of ligaments, thereby contributing to the whiplash mechanism. Prior to unexpected rear-end motor vehicle accidents, the suboccipital 
musculature may be relaxed, and the flexion of the upper Cspine is restricted chiefly by the tectorial membrane, the longitudinal fibers of the cruciate ligaments, and the transverse ligament. These structures serve as tension bands, several of which extend from $\mathrm{C} 0$ to $\mathrm{C} 2$ and prevent excessive motion at the atlantoaxial motion segment by keeping $\mathrm{C} 1$ firmly enfolded between C0 and C2 [19]. Axial rotation is primarily restricted by alar ligaments, supported by tectorial membrane, the accessory atlanto-axial ligaments and joint capsule [20], but when trauma or inflammatory disease negatively impacts alar ligaments, increased axial rotation in the occipito-atlanto-axial complex may ensue. As noted earlier, an abnormally heightened atlanto-axial rotation reduces blood flow in the contralateral vertebral artery, potentially resulting in vertigo, pain and cervical nystagmus [21], which accompany rotary hypermobility due to stimulation of pain and mechanoreceptors of the synovial joint capsule [22].

Apart from whiplash, stimulated pain responses and altered joint athrokinematics can also be observed in population with postural conditions, often due to a compromise in the surrounding joint's ROM [23]. Whether the postural deformity is due to innate genetic or environmental (occupation) factors, upper extremities and head can become positioned more anterior to the trunk (also known as forward head posture), often for prolonged periods of time. Such a structural compromise of the C-spine can compromise the ligaments ability to resist creep (FIG 1), and accelerate early degenerative and spondylogenic changes, particularly in the weight-bearing zygapophyseal joints [24]. Space is steadily minimized with the upper cervical segments twisting backward onto each other; as such, the compression triggers both the greater and lesser occipital nerves to anastomose with the trigeminal nerve [25], potentially leading to symptoms such as tinnitus and vertigo. Increased tensile stresses associated with an imbalanced posture can form traction spurs, which may encroach upon nerve roots as well as ligamentous structures [26]. Postural abnormalities place undue stress on vertebrae of the lower neck, contributing to degenerative disk conditions. Being amongst the most vital functional and structural components of the human spine, the intervertebral disk is of unparalleled importance in maintaining spinal stability. Upon structural alteration, spinal degeneration occurs, contributing to the risk of instability [27]. Abnormal stresses caused by spinal instability have been previously shown to precipitate apoptosis of disc cells and endplate chondrocytes [28]. Increased apoptosis engenders decreased production of extracellular matrix proteins, which in turn reduce the osmotic forces within the nucleus pulposus, prompting loss of water content and structural integrity, and degeneration of intervertebral discs [29]. Normal disk height is considerably reduced, and subluxation of the joint surface occurs- a phase marked by an increase of abnormal spinal segment movement and potential involvement of spinal cord and nerve roots [30].

Vertebral column stability is maintained by the integrity of all the anterior elements of support plus one posterior element, or conversely, all the posterior and one anterior element. The former components include the yellow and intertransverse ligament, capsule and facet joint, as well as the interspinous and supraspinous ligaments. Anterior elements include anterior and posterior longitudinal ligament and all the anatomical structures in front, such as the posterior and anterior halves of the intervertebral disk. Loss of functional capacity or impairment of the functional spinal unit may generate instability. Accurately defining and diagnosing this pathological condition and corollary syndromes is controversial because of the lack of information and unifying interpretations. The concept of instability was first introduced in 1949 by Nicoll [31], who highlighted the importance of a ligamentous system's integrity as a factor of vertebral stability. A biomechanical approach was investigated by Pope and Panjabi [32], who advocated that a reasonable definition of instability is loss of motion segment stiffness, such that application of force to motion segment may produce greater displacement than observed in normal structures. Despite lacking uniformity of opinion in the literature, authors acquiesce that the degree of local pathology and instability depends on a number of common entities, including ligamentous tension, tenderness or pain, and progressive deformity like general posterior and anterior ligamentous thickening and intervertebral disk changes produced by diminished joint mobility [33]. The concept of instability being associated with pain and neurologic complications is commonly accepted without much diverging opinions. Ebraheim et al [34] determined that lower cervical translation in flexion may have an adverse impact on the spinal canal diameter. In the case of anterolisthesis or posterolisthesis of $3.5 \mathrm{~mm}$ or more, some vertebral segments may generate compression or irritation with a clear neurological deficit.

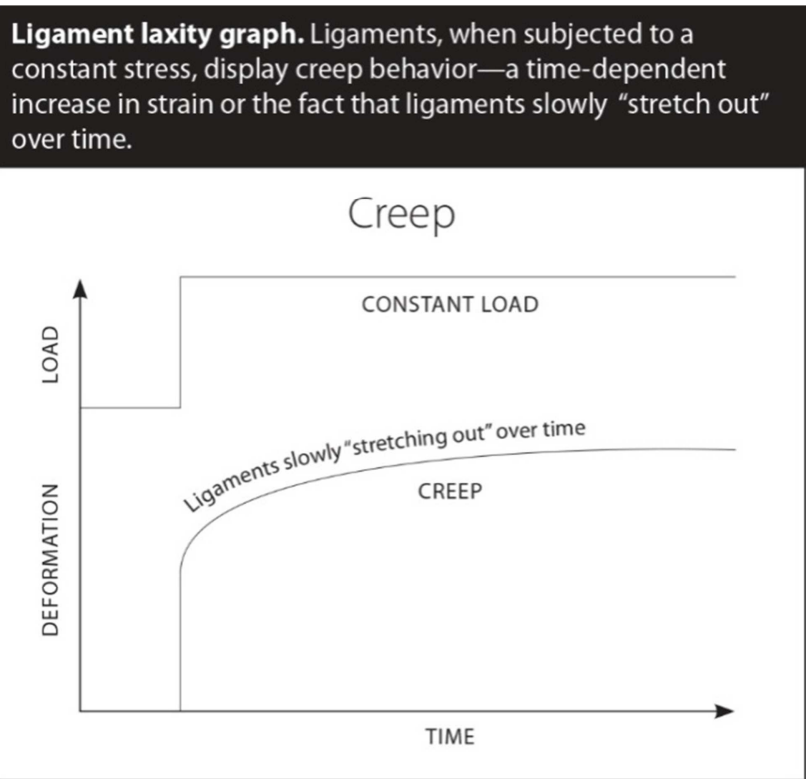

Fig. 1. Ligament laxity graph. 


\subsection{Clinical Diagnosis and Imaging}

From a mechanical and structural point of view, the cervical spine is a complex mechanism designed for substantial mobility, but it lacks stability. As such, aberrant motion can potentially disrupt its ability to maintain normal displacement patterns under physiologic loads, promoting deformity as well as potential neurologic irritation and incapacitating pain [35]. Despite numerous diagnostic identifiers suggesting CCSI, a compelling and acceptable criterion standard does not yet exist. Consequently, the condition is ostensibly linked to degeneration, kinematic measurements of anterior to posterior shear [36], abnormal or excessive coupling of the cervical spine and unquantifiable physical examination findings. From a therapeutic standpoint, because of the potential chronic nature of CCSI, the treatment should address the underlying pathology as well as reduction of chronic neck pain, with the goal of enhancing the function of the cervical spinal stabilizing structures, decrease stress on adjacent spinal segments, and thereby improve quality of spinal motion, long-term.

A Delphi study [37] of physical therapists reported that "clinical cervical spine instability may demonstrate only subtle symptoms and clinical examination features and frequently normal radiographic findings. At present, although numerous diagnostic identifiers are suggested for CCSI, a valid and effective criterion standard does not exist." CCSI diagnosis presents a challenge to health care providers, and as such diagnosis currently depends mostly on patient history. According to the Delphi study, the most common symptoms associated with CCSI include, but are not limited to the following: intolerance to prolonged static [neck] posture, past history of cervical spine trauma, clicking/popping sensation, sharp neck pain with sudden movements, frequent need for self-manipulation, inability to hold up head, muscle stiffness, increased symptoms with neck movement (i.e. rotation), and vertebrobasilar symptoms such as dizziness and headache.

The standard for measuring cervical instability is considered to be cervical flexion extension radiography [38], since motion of the individual spine segments cannot be readily determined by a physical examination. As noted earlier, C-spinal stability depends on bony structures to some degree, though more-so on ligamentous structures, so any abnormal bony motion may be indicative of ligamentous impairment and instability. Several diagnostic methods are available to evaluate the cervical spine, which if combined with radiography may increase test result sensitivity. After all, when testing for soft tissue injuries, it may be arguable that radiographic evidence of subluxation or dislocation is merely indirect evidence for ligament injury, and direct imaging of soft tissues may be warranted for a true diagnosis. Monitoring the full arc of spinal segmental motion may detect anomalous motion, including hypermobility, anterolisthesis, widening of facet joints, and lateral translation of $\mathrm{C} 1$ on $\mathrm{C} 2$, and thereafter confirm or deny the presence of potential functional loss and structural damage [39] (FIG 2). Hino et al [40] noted that for evaluation of conditions that may not be readily identified through conventional radiographic examinations, dynamic motion analysis using cineradiography is a valuable adjunctive diagnostic option. Specifically, C-spinal motion patterns were evaluated in both a normal population and in patients with cervical instability in order to determine normal vs pathologic cervical segmental motion patterns. Through continuous movement analysis, cineradiography quantified cervical motion (C1-C2 to $\mathrm{C} 5-\mathrm{C} 6)$ during flexion from the maximum extension position. In normal $\mathrm{C}$-spines, the authors observed a "well-regulated stepwise motion pattern," which commenced at $\mathrm{C} 1-\mathrm{C} 2$ and proceeded to the lower segments. Conversely, pathologic spines demonstrated a "different order of onset of segmental motion." In rheumatoid arthritis patients that exhibited atlantoaxial subluxation, C1-C2 motion commenced considerably earlier than C2-C3 motion. The cineradiographic motion analysis observed that in the patients with $\mathrm{C} 2$ or lower segmental instability, segment motion preceded that in the upper intact segments.

Clinical diagnostic methods that evaluate the integrity of ligaments (passive stabilizers) or the muscles (active stabilizers) of the cervical spine typically offer minor conclusive evidence and are inundated with an unacceptable degree of reliability [41]. Except for apparent subluxations [42 ] and atlanto-axial rotary fixations [43 ], clinically diagnosing rotary hypermobility and instability is challenging. In this case, magnetic resonance imaging (MRI) might be an effective alternative on account of its enhanced sensitivity for soft tissue and spinal cord injuries. This advantage suggests that MRI may potentially be the favored diagnostic tool for ligamentous injury, although various disadvantages exist that may preclude its widespread adoption. In spite of the drawbacks, MRI remains a viable screening test for patients with a high risk of cervical spine instability, outperforming even CT scans for detecting ligamentous injuries and visualizing the collagen integrity of soft tissue structures [44]. But ultimately, notwithstanding the specificity and sensitivity of the mandated evaluation, a reliable and accurate protocol for clearing the cervical spine must be established to facilitate organized diagnostic evaluations, and decrease the risk of missed injuries. Thereafter, health care resources can be used more efficiently and medical tests as well as intervention safety and efficacy can be maximized.

Because cervical sprain and/or strain (restricted movement) may preclude the use of CT or MRI due to the imaging technique's limited functions in visualizing capsular pathology and controlled maximum rotation via cervical side bending, functional MRI (fMRI) may be preferable for visualizing impaired ligaments and joint capsule, and accompanying pathoanatomical motion patterns in patients with injuries of the upper segments of the C-spine (craniocervical joint complex) [45]. Visualization of the injury may be more readily rendered by the fMRI on account of its dynamic nature, such that 40 select positions are performed, demonstrating pathological movement patterns and injuries to the ligament and joint capsules [46]. In a study [47] observing 3 patients with severe whiplash trauma, 
extensive preliminary examinations (MRI, CT, and X-ray, respectively) failed to find any structural lesions. Upon undergoing an fMRI examination as well as surgical fixation, previously undetected injuries to joint capsules were promptly observed. While fMRI is not indicated for every patient with distortion of the $\mathrm{C}$-spine, the study noted that the three cases shared distinct clinical features, serving as "prima facie" indications for an fMRI, such as headache, numbness, development of neurological disturbances of upper and lower limbs, difficulty reading, and other symptoms consistent with instability of the $\mathrm{C} 1 / \mathrm{C} 2$ segment.

There are as of yet few methods that assist in the evaluation of suspected lesions affecting soft tissues, particularly distortion of ligaments of the upper C-spine. Like the fMRI, diagnostic recognition of instability and coexisting intra-ligamentous malfunction may be visualized by functional or 3D computed tomography (fCT) as it renders sufficient objective evaluation of rotatory segmental motion [48] (FIG 3). Axial rotation is the upper cervical spine's dominant motion while flexion/extension is mainly exhibited from C2-T1 [49]. While measuring such regional spinal unit motion is challenging, functional radiography has shown to offer reliable data in evaluating flexion/extension, in regards to rotation, translations and centers of rotation [50 ]. Functional $\mathrm{x}$-rays in lateral view during flexion/extension may offer some data about instability, but functional CT may be helpful in recognizing rotatory hypermobility or instability [51]. In particular, this method is useful for visualizing the degree of axial rotation at the occiput-atlas and atlas-axis levels, and segments below, which may increase following trauma-induced lesions of the alar ligaments.

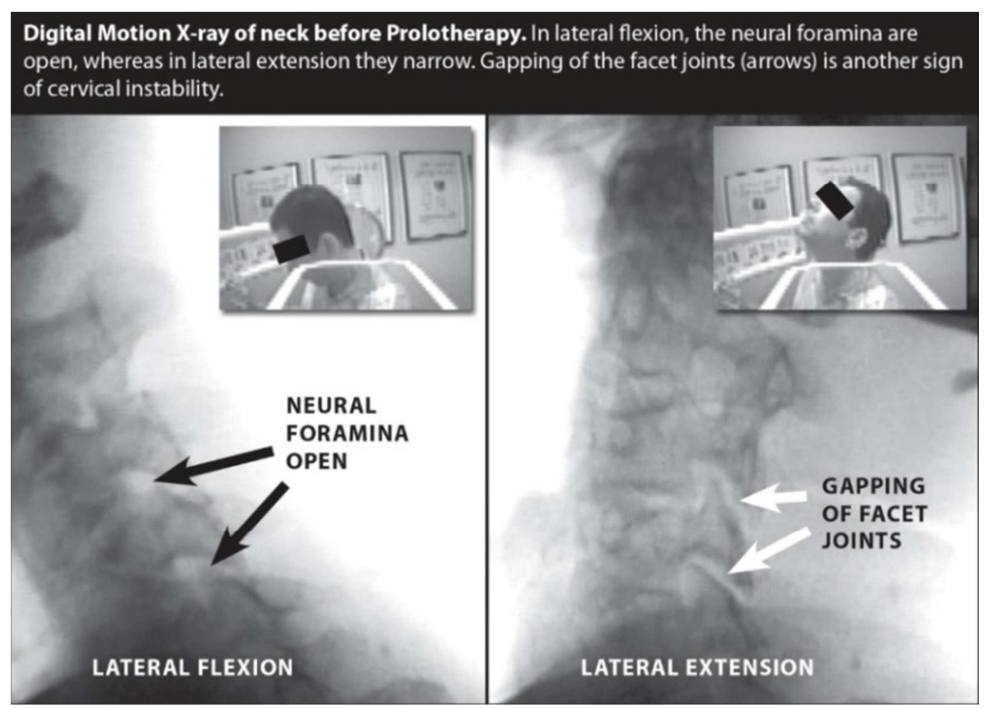

Fig. 2. Digital Motion X-ray of neck before Prolotherapy.

3D CT scan of upper cervical spine. C1-C2 instability can easily be seen in this patient, as $70 \%$ of $\mathrm{C} 1$ articular facet is subluxed posteriorly (arrow) on C2 facet when the patient rotates his head (turns head to the left then the right). This can cause a myriad of symptoms, including headaches, neck pain, vertigo, tinnitus, and dizziness.

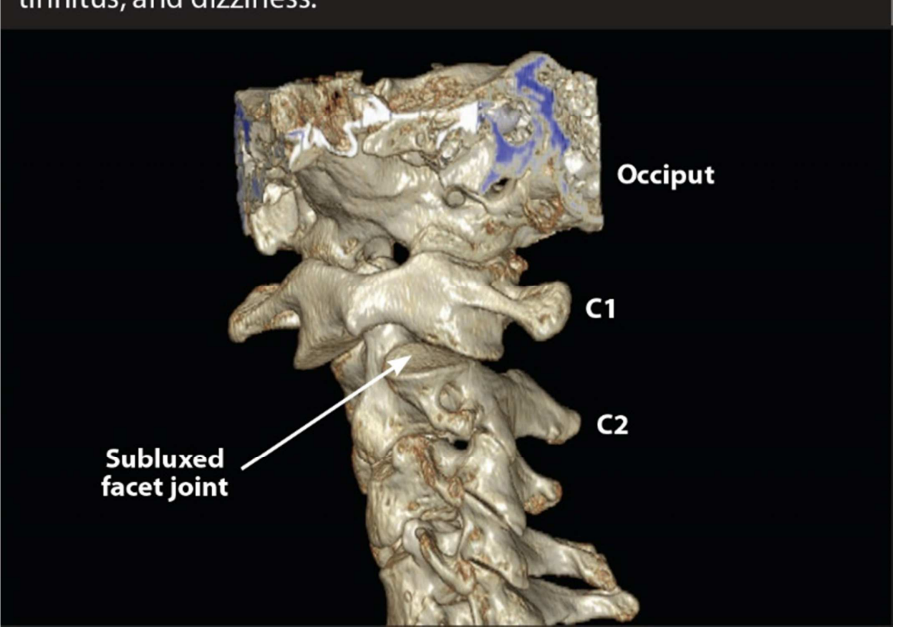

Fig. 3. 3D CT scan of upper cervical spine. 


\subsection{Capsular Ligament Injury as a Source of Chronic Neck Pain}

Facet joints have been implicated as clinically important sources of chronic neck pain. Lord et al [52] demonstrated in a placebo controlled whiplash study that the prevalence of C2-C3 facet joint pain in patients suffering from chronic neck pain was 50 percent. Manchikanti et al [53] systematically evaluated 500 consecutive patients with chronic, non-specific spine pain to determine prevalence of facet joint injury by spinal region. In patients with cervical spine pain, prevalence of facet involvement was 55 percent; 42 percent in thoracic spine pain, and 31 percent in lumbar spine cases. The authors concluded that facet joints are significant pain generators in a large proportion of patients with chronic spinal pain. Morphologically, this may be due to the fact that spinal facet or zygapophysial joint capsules are highly innervated by medial branches of the dorsal rami [54] - as such transmitting pain in the neck, upper, mid and low back, along with intervertebrtal discs, nerve root dura, ligaments, fascia and muscles, with pain referred to the head, upper and lower extremity and chest wall $[55,56]$.

In spite of the heavy innervation, facet joints are poorly vascularized, and the poor blood supply impedes an efficient healing process, triggering scar tissue formation and adhesive capsulitis within the joint, leading to chronic dysfunction and pain [57]. The capsular ligament is highly innervated, and composed of crimped, dense collagen fiber bundles linked by proteoglycans, with interspersed elastin fibers and fibroblasts. Under load, the collagen fibers may become uncrimped, which permits the overall joint to rotate and translate without generating any mechanical resistance. When impaired, it is hypothesized that collagen fibers are implicated in facet capsule laxity [58]. For instance, degeneration of the facet joint cartilage alters joint mechanics due to wear of the articular layer; such thinning may be correlated to an increased rate of capsular ligament degradation due to altered joint mechanics [59]. Fujiwara et al [60] investigated spinal motion changes in association with facet cartilage degeneration, and concluded that together with spondylolisthesis, degenerative thinning of cartilage may precipitate spinal segment hypermobility and laxity of facet capsules. This may be due to scar tissue proliferation, which develops to reconnect collagen fibers that were impaired by resisting increased tensile stresses generated by the segment's hypermobility. Capsular ligament failure may also undermine fibroblasts involved in the remodeling of its injured tissue [61] As such, the poorly repairing capsular ligament may be at an increased risk for further injury, degeneration and loss of mechanical integrity. Fewer undamaged collagen fibers support ligament loads, which can likewise augment the risk of damage. Concurrently, a greater stress on fibroblasts may induce their production of aberrant proteins, which are less advantageous for the repair of the ligament extracellular matrix to maintain its mechanical processes. Accordingly, repairing the capsular ligament is integral through correct treatment protocols, which aim to boost mechanotransduction mechanisms critical to restoring function and biomechanical integrity of the facet joints and stability of the structural column [62].

A salient feature of cervical facet joints are the mechanoreceptors and nociceptive nerve endings [63], richly innervated by medial branches of the segmental dorsal rami as well as those above and below, which may account for the broad referral patterns [64] (FIG. 4). Barnsley et al [65] observed multiple levels of symptomatic facet joints, with the two most common double-level patterns being $\mathrm{C} 2 / \mathrm{C} 3$ with $\mathrm{C} 5 / \mathrm{C} 6$, and $\mathrm{C} 5 / \mathrm{C} 6$ with $\mathrm{C} 6 / \mathrm{C} 7$. $\mathrm{C} 2 / \mathrm{C} 3$ and higher facet joints produce neck and sub-occipital pain, as well as headaches, while joints below can produce neck, upper arm, interscapular and shoulder pain.

Panjabi et al [66] delineated the facet articular cartilage, synovial fold, and facet capsule as at-risk structures for whiplash-like injuries due to excessive facet joint compression or capsular ligament strain. Specifically, the authors noted that risk to facet joint components may be associated with facet compression during rear impact accelerations $\geq 3.5 \mathrm{~g}$, as capsular ligament strains exceed the physiologic strains at $6.5 \mathrm{~g}$. As such, even relatively low impact collisions may generate facet impairment

Besides facet capsule injury as a hypothesized mechanism for neck pain (as well as headache and shoulder pain), a variety of $\mathrm{C}$-spinal structures may be responsible, including intervertebral discs, dorsal root ganglia, ligaments and muscles. In an anatomical investigation of the human cervical facet capsule, Winkelstein et al [67] quantitatively demonstrated that the semispinalis, multifidus, and rotator muscles are in close proximity to the cervical facet capsule, and substantial muscle insertions into the facet capsule ligament may be responsible for possible mechanism of injury to the ligament-facet complex due to cervical muscle activation during particular neck muscle loading. Notably, the study results exhibited that 22.4 percent of the human lower cervical facet capsule area is covered with muscle fibers, implying a potential path for facet capsule loading. Using a scale of 1.5 to estimate the force for stimulated muscles undergoing rapid elongation (as in whiplash injury), the authors observed that the loading of the facet capsule due to muscle contraction may be as high as $51 \mathrm{~N}$. Facet capsule injury may occur at loads ranging from 48 to $121 \mathrm{~N}$ [68]. When the capsular ligament in the lower cervical facet joints exceeds its physiologic limit during traumatic altered spinal kinematic [69], injury may result in facet-mediated neural responses [70], displaced soft tissue and deformation, as well as minor ruptures and strain (ranging from 35 percent to 64.8 percent in shear and tension) [71]. Iatridis et al [72] suggest that such micro-trauma following sub-failure loading alters the mechanical properties of the tissue, increasing laxity, decreasing stiffness, altering viscoelastic properties and, ultimately inducing persistent activity in the nervous system.

Aside from chronic neck pain, patients with cervical instability due to injury of the facet joints may also develop a 
myriad of symptoms known as Barré-Liéou syndrome. Those with Barré-Liéou Syndrome (posterior cervical sympathetic syndrome) may be predisposed to developing secondary symptoms like restlessness, irritability and poor concentration [73], which may potentially progress into a chronic state. As such, careful examination of the primary clinical presentations is imperative for an accurate diagnosis and successful resolution. Characteristics of Barré-Liéou syndrome include presence of headache, vertigo, dizziness, facial pain, visual disturbances, neck pain, and ear pain and are thought to be resultant from cervical instability with encroachment on the cervical sympathetic nerves. Headaches may also result from internal and external carotid vessel spasming, while sympathetic vasoconstriction of the internal carotid artery may lead to ischemia of the brain and subsequent vertigo. The remaining constellation of symptoms, including tinnitus can result from sympathetic stimulations of caroticotympanic nerve, reduced blood flow in various arteries such as the carotid, vertebral and ophthalmic, and altered communication with the trigeminal ganglion. Treatment of these symptoms is challenging because of the lacking evidence for a definite diagnosis; however, because vertebral misalignment, hypermobility and subsequent nerve compression may precipitate Barré-Liéou Syndrome, using diagnostic tools to determine CCSI may be the first step to combating it.

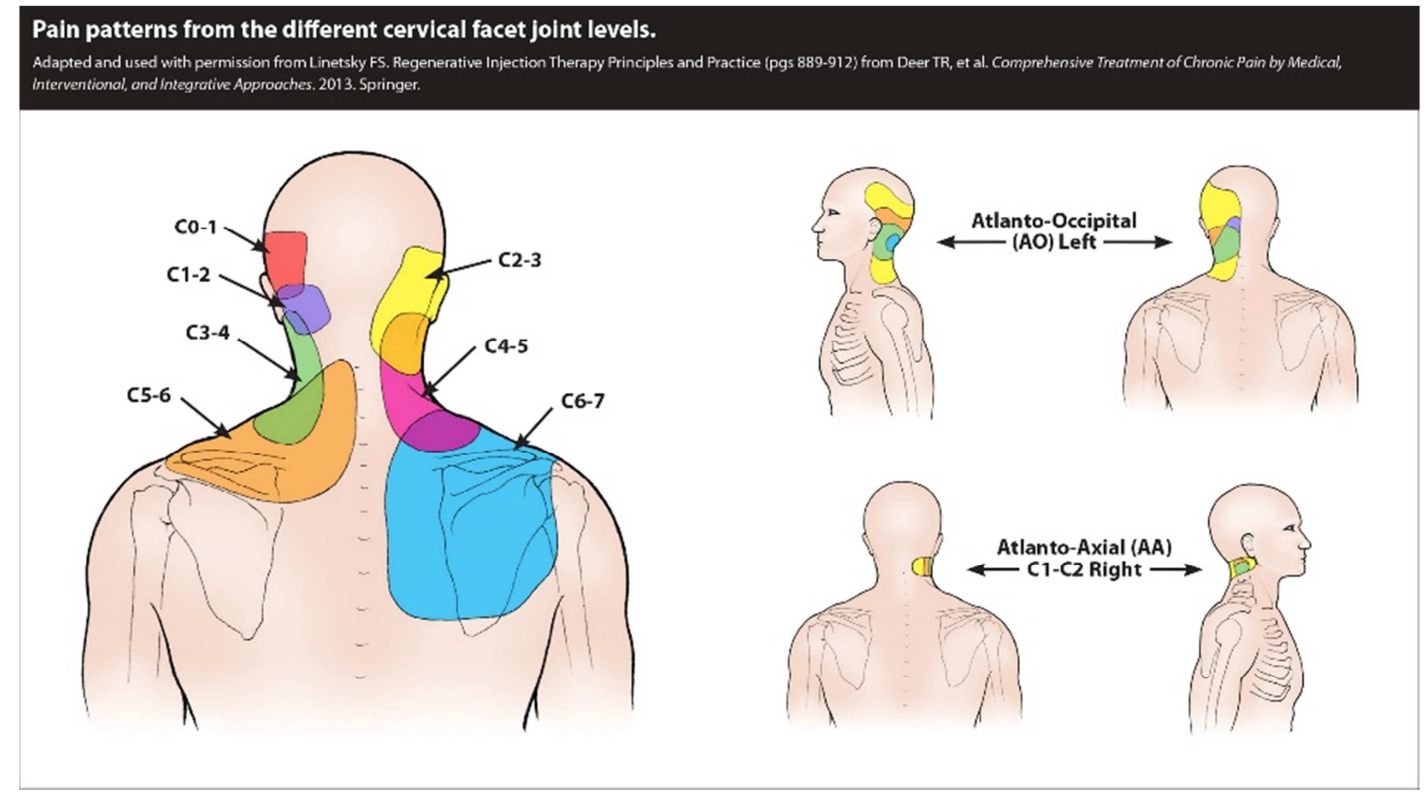

Fig. 4. Pain patterns from the different cervical facet joint levels.

\section{Interventions}

\subsection{Spinal Manipulation Therapy}

A significant proportion of healthcare practice is dedicated to care of musculoskeletal spinal conditions [74], with millions of dollars spent annually on treatment, lost wages, and compensation [75,76]. Despite the magnitude, costs and morbidity of neck pain, remarkably limited research has investigated treatment for patients with this condition [77], though it is assumed that spinal manipulation therapy (SMT) can offer short-term relief [78]. This therapeutic intervention encompasses a range of manual maneuvers that stretch, mobilize or manipulate the spine, paravertebral tissue and other articulations to mitigate neck pain and stiffness, migraines, muscle-tension headaches and improve locomotor function [79].

Despite widespread use of SMT for chronic neck pain, systematic reviews have found limited evidence and insufficient data on the therapy's short and long-term effectiveness $[80,81,82,83]$, while clinical trials may be too small to evaluate risk of rare complications [84,85]. Many published case reports have linked neck manipulation to vertebral and carotid artery dissection and insufficiency $[86,87,88]$; after all, arteries are uniquely susceptible to mechanical injury due to their relationship to the adjacent bony structures and ligaments. The three sites most susceptible to external forces include: atlanto-axial (C1-C2) junction, craniocervical junction and ascent in the foramina of the first 6 cervical vertebrae [89]. Ultimately, SMT has the effect of increasing mobility, which can further irritate already damaged structures $[90,91]$. The resultant movement of the target vertebrae does not solely depend on the magnitude and direction of thrust force, but on constraints of vertebral movements, such as potentially unstable or lax ligaments, bony contacts and disks.

\subsection{Surgery}

When a cervical spine fracture is identified, subsequent management is seemingly straightforward; however, appropriate management of a ligamentous cervical spine injury without fracture is less certain. Surgery is commonly performed particularly when CCSI with neurologic involvement is presented- anterior cervical fusion being the primary procedure [92]. Over 300,000 spine fusions are 
performed annually in the United States, the vast majority of which target degenerative diseases of the spine. One study [93] demonstrated a 220 percent increase in spinal fusion surgery between 1990 and 2000, in spite of the absence of clarified indications or new demonstrations of efficacy. Expert opinions echo this sentiment, estimating that fewer than half of fusions are appropriate [94].

As the standard of care is steadily shifting toward greater use of spinal fusion, there remains limited objective evidence in the literature to support its value in significantly reducing pain and improving stability. In patients that underwent fusion, Munro [95] observed reduction in the incidence of pain by two-thirds but no remarkable stability recovery. Brav et al [96] compared a number of fused and non-fused patients, in terms of recovery and hospitalization recumbency time, and concluded the overall prognosis to be essentially the same in both groups. Conversely, other studies demonstrate that cervical spinal fusion is usually successful in relieving symptoms, but there is no statistical significance in the quality-adjusted life years between the operative and nonoperative groups [97]. These conflicting data are significant, considering the associated societal and healthcare expenses, including per-surgery costs, potential surgical revision, length of post-surgical rehabilitation, missed work (disability) and loss of productivity, and increased comorbidities [98] that predispose adjacent levels to increased stress [99] and acute, traumatic instability [100]. Previous studies have reported chronic degenerative changes in joints adjacent to the fused mass, manifested as disc degeneration, facet joint arthrosis, and myeloradiculopathy [101]. Steady development of disc and facet arthrosis in cervical joints adjacent to fusions has also been reported for degenerative spine conditions [102]. While complex surgical correction and realignment may doubtlessly be indicated in cases of severe threat to neurologic structures, oftentimes treatment time and expenses can be significantly minimized by implementation of more appropriate conservative (noninvasive) treatment approaches that target the root of the problem (FIG 5).

In regards to ensuing medical complication associated with the progression of care, adjacent segment disease (ASD) may result from multiple sequential cervical fusions, as reported in the clinical outcomes of 888 patients studied to determine the long-term effects of repeat cervical fusions [103]. Indeed, spinal fusion have demonstrated clinical success in relieving pain and improving neurological symptoms, but the benefits must be weighed against the risks, in terms of complications, expenses and quantity of acceptable procedures.

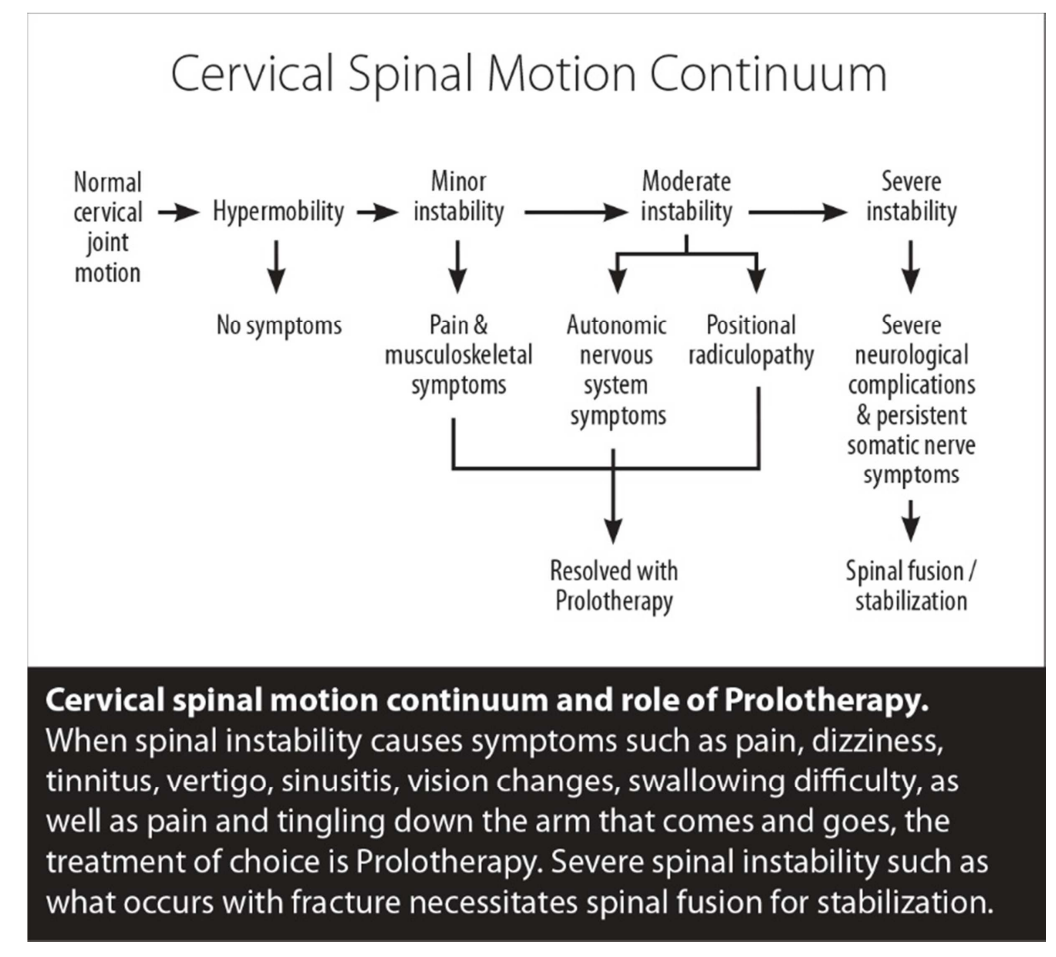

Fig. 5. Cervical Spinal Motion Continuum.

\subsection{Corticosteroids \& NSAIDs}

On account of chronic pain associated with clinical cervical spine instability, patients may experience a reduced qualify of life, depression, loss of sleep and poor concentration. As such, in conjunction with traditional physical treatment modalities and therapy, patients may opt for treatment with analgesic medication to improve psychosocial and physical function. As recommended by the
World Health Organization (WHO), acetaminophen and nonsteroidal anti-inflammatory drugs (NSAIDs) are on the first rung of the analgesic ladder to mitigate mild to moderate pain [104]. Notwithstanding the risks and contraindications of analgesic medication, studies $[105,106]$ have shown that NSAIDs are not recommended due to their inhibition of soft tissue healing mechanisms, which are key for CCSI conditions. Specifically, the authors observed that the 
prescribed anti-inflammatory drugs hampered the inflammatory proliferative phase of healing (days 0-4 post injury), and delayed muscle regenerative processes, respectively. In the study investigating the use of ibuprofen for tendon injuries, it was observed that at four weeks, the non-steroidal drug decreased the strength of flexor tendons undergoing repair by 300 percent [107]. While the short-term pain relief from NSAIDS is useful, long-term chronic pain management with the medication is unfavorable, considering the inhibition of fibroblast growth (crucial for ligament and tendon repair), as well as interference with prostaglandin initiation, proteoglycan synthesis and other functions, which are key in accelerating healing.

Like NSAIDs, corticosteroids suppress processes that initiate the inflammatory healing response, thereby decreasing collagenase, and inhibit formation of granulation tissue and prostaglandins, which increase circulation and recruit immune cells to injured sites [108]. Numerous studies $[109,110]$ have shown that corticosteroids, like cortisone (or hydrocortisone), may lead to a decrease in bone, ligament and tendon strength. In one experimental study [111] examining corticosteroid injections into tendons, 100 percent of the tendons exhibited nercrosis at the site of injection. A recent study [ 112 ] comparing the effectiveness of corticosteroid injections with Prolotherapy for lateral epicondylosis (LE) noted that the most common treatment for LE is corticosteroid injections. The authors went on to say that while this treatment is used to reduce inflammation in subjects with a variety of tendinopathies, histologic studies suggest that inflammation is not a major feature of the condition, but rather a failure of normal tendon repair mechanisms related to angiofibroblastic degeneration [113]; as such, the rationale for the use of the injections is misguided. In fact, the authors noted that inflammation may actually be a favorable facet of the response to injury and healing processes so inhibiting them may be counterproductive [114]; moreover, numerous treatments like NSAIDs, steroidal injections, and even rest, braces, activity modification and physical therapy have proved to be generally ineffective [115]. As such, given the lack of evidence for long-term corticosteroid benefits, the need for alternative injectable agents is essential to improve function and reduce pain.

\subsection{Other Nonoperative Interventional Techniques}

Management of chronic spinal pain with interventions like physical therapy and injectable techniques like facet joint nerve blocks, as well as intramuscular and epidural spinal injections, offer short-term symptomatic and pain relief but may have unclear long-term benefits [116]. There have been several systematic reviews [117] and trials [118 119,120] investigating the use of structured physical therapy programs for the treatment of cervical spondylosis and its sequelae. Limited conclusions could be derived regarding its efficacy; however, individually tailored physical therapy in conjunction with other procedures have demonstrated improvement in pain relief and sensory function. A study by
Olson et al [121] concluded that while physical therapy may effectively reduce mechanical stresses on passive components, its ability to restore a compromised passive subsystem is questionable. Similarly inconclusive results have been observed in studies $[122,123]$ investigating the use of Botulinum Toxin A injections to treat pain conditions like headache, dystonia, muscle spasticity, and myofascial pain arising from trigger points. Epidural steroid spinal injections administered via a translaminar or transforaminal route to target specific nerve roots have been shown to provide up to 6 months of pain relief, though long-term benefits are variably effective, and complications as well as side-effects, like anxiety, cataracts and stomach ulcers, may compound the unreliability of the intervention [124]. According to a literature synthesis [125] examining facet joint nerve blocks, evidence for therapeutic lumbar intraarticular facet injections was moderate for both short and long-term improvement, and limited for cervical facet joint injections. Evidence for cervical medial branch blocks was moderate.

\subsection{Prolotherapy for Clinical Cervical Spine Instability}

Standard treatments such as SMT and surgery likely do not promote soft tissue healing through the body's own remarkable musculoskeletal repair processes. Prolotherapy ("proliferative" therapy) is a regenerative injection therapy that is predicated on the body's inherent capacity to heal via the inflammatory cascade (FIG. 6), provoked by the administration of sclerosant or autologous solutions that trigger inflammatory and healing responses. Prolotherapy pioneer Dr. George S. Hackett broadly defined the nontraditional therapy as "the rehabilitation of an incompetent structure by the generation of new cellular tissue." As such, this orthobiologic procedure involves the injection of mild irritants directly into injured soft-tissue, ultimately galvanizing the body's stagnant (or prematurely aborted) regenerative processes by jump-starting the production of new tissue at the fibrous junction with the bone. The irritant solutions act on lesions by eliciting temporary, low-grade inflammation at the injury site, in turn encouraging the initiation of the inflammatory healing cascade. Common injectant solutions used for this purpose can be 15 percent hypertonic dextrose, polidocanol, manganese, or sodium morrhuate mixed with an anesthetic such as lidocaine or procaine, delivered directly into the fibro-osseous junction. Other common solutions include human growth hormone (HGH), testosterone, and zinc. Thus, the first stage of the wound-healing cascade is initiated, precipitating vital inflammatory responses like fibroblast and platelet activation that repair and reinforce injured connective tissue. A more aggressive proliferant (which may be needed in those with more severe symptoms), termed cellular Prolotherapy, includes the use of the patient's own cells, such as platelet rich plasma (PRP), bone marrow or adipose tissue, which contain progenitor cells. In some cases, this may be preferable on account of the potent concentration of platelets, which like dextrose locally prompt the inflammatory response and enhance the recruitment, proliferation and 
differentiation of cells involved in regeneration. The rationale for PRP rests in the supra-physiologic concentration of platelets releasing a variety of bioactive proteins (growth factors) responsible for attracting macrophages, mesenchymal stem cells, and osteoblasts that respectively promote necrotic tissue removal, collagen synthesis and healing.

The use of proliferants to treat chronic pain, underlying instability, and associated sympathetic symptoms [126] (FIG. 7) has a long history, with positive biological responses documented in a variety of studies. Case reports [127] reviewing Prolotherapy for whiplash-related chronic neck pain, to open-face prospective and double-blind, placebo controlled studies [ 128 ] have documented clinically significant improvements in pain reduction. Similarly favorable results were observed in a double blind clinical study by Ongley et al [129], in which more than 50 percent of patients with chronic lower-back pain experienced significant improvement, following dextrose/phenol/glycerin vs. saline injections. More successful results were noted by Bourdeau [130], who published a 5-year retrospective survey of patients treated with Prolotherapy for lower back pain, citing a 70 percent improvement. Klein et al [131] presented a randomized, double-blind clinical trial of 79 patients who previously failed conservative treatments for chronic low back pain. Following a 6-month evaluation, 30 of the 39 patients randomly assigned to the proliferation treatment group achieved a 50 percent or greater decrease in pain.

Studies $[132,133]$ have been published on favorable cervical Prolotherapy outcomes. In a retrospective case series, Hooper et al [134] investigated the clinical benefits of intraarticular regeneration injections (Prolotherapy) for chronic whiplash related neck pain. 20 percent dextrose solution was injected in patients identified as having ligament laxity of the zygapophysial joint. The authors concluded that the procedure improved pain, function, and appeared safe and highly effective in addressing the underlying pathology, rather than just treating the symptoms. In a separate retrospective case series, Hooper et al [135] investigated the clinical benefits of dextrose Prolotherapy for patients with a history of chronic spinal pain. One hundred and seventyseven consecutive patients completed Prolotherapy treatment (performed on a weekly basis for up to 3 weeks) and were followed for a period spanning from 2 months to 2.5 years. Patient-reported outcomes demonstrated a 91.0 percent reduction in pain level; as well as 84.8 and 84.3 percent improvement in daily living activities and ability to work, respectively. Recent research, using flexion/extension x-rays to study C-spinal instability and fluoroscopically guided cervical Prolotherapy, exhibited statistically significant correlations between a reduction in both cervical flexion and extension translation and improvement in the patient pain level [136]. Although such results are promising in regards to the management of neck pain, an observational study [137] examining Prolotherapy for unresolved neck pain also considered quality of life measurements. The results of the uncontrolled study demonstrated that Prolotherapy may decrease pain and improve quality of life in patients with unresolved neck pain. Notably, decreases in pain, stiffness and crunching levels achieved statistical significance even in subjects whose medical doctors conceded that surgery was the only option for treating their neck pain. Other studies $[138,139,140,141,142,143]$ report favorable results with Prolotherapy for C-spine related trauma.

\section{The Biology of Prolotherapy}

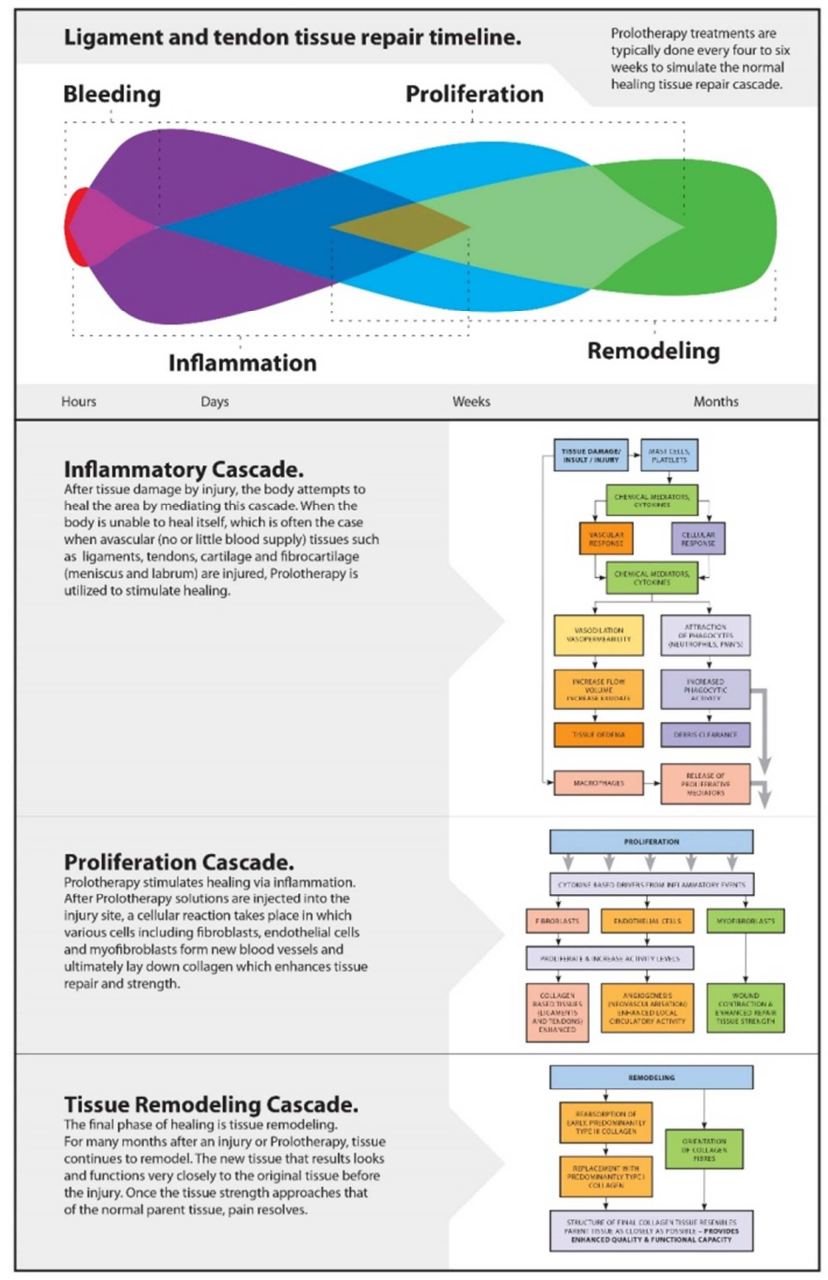

Fig. 6. The Biology of Prolotherapy. 


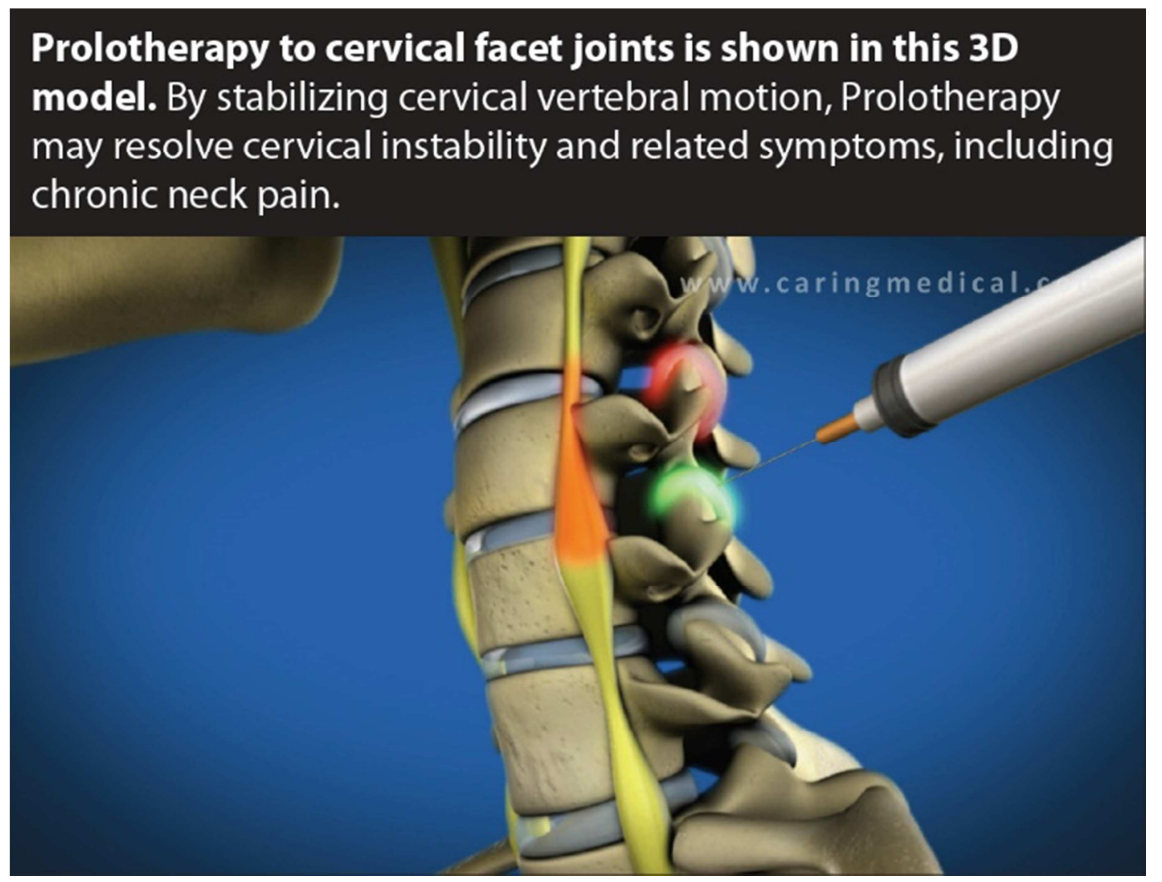

Fig. 7. Prolotherapy to cervical facet joint is shown in this $3 D$ model.

\section{Materials and Methods}

\subsection{Patients}

This study involved 21 patients (13 women and 8 men) out of 23 consecutive patients who sought treatment for $\mathrm{C} 1-\mathrm{C} 7$ cervicalgia. The 21 patients characterize all the qualifying criteria- they were treated with Prolotherapy for chronic neck pain at our private pain clinic from 2008 through early-2013. Patient inclusion criteria were age $\geq 18$ (average patient age was $44 \pm 12$ ); upper cervical instability due to traumatic or degenerative causes; neck pain with associated symptoms; sub-occipital headaches and/or migraine headaches; tenderness in upper $\mathrm{C}$-spine and occipito-cervical junction; ligament laxity precipitated by instability; symptoms greater than 6 months; positional radiculopathy (defined as intermittent numbness, tingling, or pain that radiates down the $\operatorname{arm}(\mathrm{s})$ as related to neck position); leg paresthesia without evidence of myelopathy; and completion of dextrose Prolotherapy treatment course at least 6 months prior to study. General exclusion criteria were rheumatoid arthritis, Down's syndrome, cervical fractures, continuous radiculopathy, and os odontoideum.

Prior to Prolotherapy, 19 patients received cervical manipulation (including self-manipulation or that performed by a licensed chiropractor), performed in a professional setting and/or self-manipulation. The total number of highvelocity treatments received ranged from 3 to hundreds. Prior to high-velocity manipulation, 47 percent of patients experienced stiffness; 28 percent limited ROM; and 52 percent crepitation/clicking/crunching. Other symptoms included headache, muscle weakness, cognitive difficulty, fatigue, nausea and tinnitus. Patients reported that these symptoms remained despite the number of manipulations that they received. In two cases, patients reported that they felt cervical spine manipulations made their symptoms worse. An average of 4 months (range 0 to 6 months) lapsed between final manipulation session and first Prolotherapy treatment.

\subsection{Intervention}

For dextrose Prolotherapy, the injection sites were first sterilized with Maxiclens (containing chlorhexidine); after which the topical anesthetic lidocaine $5 \%$ cream was applied, and wiped clean using hydrogen peroxide and ChloraPrep after 10 to 15 minutes. All patients were treated with a 15 percent dextrose, 0.1 percent procaine, and 10 percent sarapin solution. 4 patients received this basic solution alone, while in 9 of the 21 cases, each syringe of this solution included an additional $0.5 \mathrm{cc}$ of sodium morrhuate $(50 \mathrm{mg} / \mathrm{mL}) .3$ patients were treated with an addition of platelet rich plasma (PRP) from their own blood. The remaining patients received the dextrose solution mentioned above with the addition of $1.0 \mathrm{cc}$ of polidocanol $(5 \mathrm{mg} / \mathrm{mL})$, $1.0 \mathrm{cc}$ of manganese $(0.1 \mathrm{mg} / \mathrm{mL})$, or a combination thereof in each syringe. This was determined based on the severity of symptoms and patient's progress, as additives increase the inflammatory response. The cervical spine ( $\mathrm{C} 1$ to $\mathrm{C} 7$ ) was injected with varying units of solution, ranging from $50-80 \mathrm{cc}$, depending on the degree of injury as well as the number of areas treated per day. The latter included bony structures of the $\mathrm{C}$-spine, such as the three basic vertebral functioning structures (lamina, transverse processes and facet joints), the mastoid process, and segments of the occiput, scapula and clavicle. Bony structure muscle attachments treated included suboccipital triangle, erector spinae group, side and anterior neck muscles, serratus anterior and trapezius, as well as both the capitis and cervicis splenius muscles. The mean number of Prolotherapy treatments was 6.6 (2 to 15). The mean 
duration of the treatment period was 15 months.

\subsection{Data Collection}

A questionnaire was distributed in which patients used a 10 point scale $(0=$ no pain and $10=$ crippling/severe pain $)$ to rate neck, head and facial pre-treatment and post-treatment pain magnitude while at rest, as well as during normal activities and exercise. The same rating scale was used to assess stiffness $(0=$ no stiffness and $10=$ extremely stiff $)$; range of motion $(0=$ no range of motion problem and $10=$ extreme limitation to range of motion); crepitation $(0=$ no crunching and $10=$ extreme level of crunching); and numbness $(0=$ no numbness and $10=$ extremely numb $)$. Multiple choice questions were used to determine pre- and post-treatment exercise ability, including: overall sustained improvement; and, average daily overall ability to exercise six weeks or more following their last treatment. The multiple choice options included: (a) no exercising restrictions (no symptoms); (b) mildly compromised; (c) moderately compromised; (d) severely compromised; (e) totally compromised.

Follow-up questions involved patients ranking the percentage of overall sustained daily improvement with regard to pain, stiffness, range of motion, crepitation, and numbness, currently to at least six weeks or longer following treatment. If the patient's sustained improvement was $<100$ percent, multiple choice questions were provided to quality the reason, including: (a) recommended number of treatments not received; (b) re-injury performing normal activities; (c) re-injury doing somewhat unreasonable activity; (d) poor adherence to doctor's exercise/muscle toning recommendation; (e) poor adherence to weight loss recommendation; (f) insufficient diet modification to improve injection efficacy; $(\mathrm{g})$ development of other medical conditions that affected Prolotherapy's potential; (h) Little benefit realized from Prolotherapy; (i) n/a. Lastly, the questionnaire considered surgery as a possible option before and after treatment. Specifically, patients were asked whether they consulted another physician or surgeon prior to receiving Prolotherapy for their respective conditions. If so, patients were asked as to whether the physician or surgeon recommended surgery, and which type of surgical procedure in particular.

\subsection{Results}

Patient-reported outcomes were obtained at a mean of 24 months following completion of treatment (range 1 to 39 months). Significant reductions ( $p<0.001[\alpha=0.05])$, were observed in pain rating for pain at rest (mean \pm SD of 5.7 \pm 3.0 at baseline vs. $1.5 \pm 1$ post-treatment); pain during normal activity (6.6 \pm 2.4 vs. $1.3 \pm 1.6)$; and during exercise (7.7 \pm 2.6 vs. $1.9 \pm 2.3)$. Pain ratings in the three categories were reduced by $82.5 \%, 80.3 \%$, and $75.4 \%$ of their baseline values, respectively. Although female patients were presented with a longer history of pain compared to males (7.6 months vs. 4.7), no significant gender difference was observed for the response of pain to treatment. For stiffness, ROM, crepitation and numbness, only patients with non-zero baselines values were analyzed. All patients had non-zero baseline values for at least one of these categories, and 9 patients had non-zero baseline values for at least two categories. With the exception of one patient who reported no gain for crunching/crepitation, all patients with non-zero baselines for these categories experienced improvement. For stiffness, ROM, crunching/crepitation, and numbness, the baseline vs. posttreatment ratings were, respectively, $5.8 \pm 3.5$ vs. $1.3 \pm 1.8$; $4.8 \pm 3.6$ vs. $1.5 \pm 2.5 ; 5.8 \pm 3.5 \mathrm{vs} .2 .2 \pm 2.6$; and, $3.2 \pm 3.9$ vs. $0.3 \pm 0.9$. No patient reported an adverse result (increased rating) for these outcomes.

Patient-reported daily overall sustained improvement (pain, stiffness, ROM, crepitation, numbness) after $\geq$ six weeks of receiving Prolotherapy was 86 percent \pm 16 percent. 7 patients of 21 (33 percent) reported 100 percent improvement, while the remaining attributed the lack of complete sustained improvement to: not receiving the recommended number of treatments (23 percent); re-injury while performing normal activities (14 percent); re-injury while performing an unreasonable activity ( 9 percent); and N/A (52 percent). 19 of 21 patients with compromised ability to exercise at baseline reported improved ability to exercise post-treatment. 8 of 21 (38 percent) reported a complete inability to exercise before treatment, and only 2 of 21 (9 percent) were capable of exercising vigorously without restriction. After treatment, no patient reported complete inability to exercise and 6 of 21 (29 percent) regained capacity for unlimited exercise. To gauge overall satisfaction with the treatment, 95 percent of patients reported "yes" in response to whether Prolotherapy met overall expectations, while one patient responded "somewhat." 11 of 21 patients (52 percent) reported that they discontinued treatment because they were either pain/symptom-free or happy with the results though not $100 \%$ relieved of pain and/or other symptoms. Prior to Prolotherapy treatments, two patients were recommended by a physician or surgeon to have a cervical fusion operation. After completing their course of treatment, neither of these patients felt they needed an operation due to relief of symptoms.

No adverse outcomes were reported.

\section{Clinical Bottom Line}

\subsection{Discussion}

This retrospective case series represents one of the few studies supporting the use of Prolotherapy in the treatment of chronic neck pain and cervical instability. The study results are compelling as they indicate a positive correlation between proliferant injections and reductions in pain and improved functionality. 20 of 21 patients reported post-treatment reduction in all three pain categories (while at rest, during normal activity and exercise), and 20 of 21 patients reported improvement in all four functional categories (stiffness, ROM, crepitation/crunching, and numbness). On the questionnaire, 95 percent of patients expressed a positive 
view of their experience with Prolotherapy, while the remaining 5 percent reported that the treatment met their expectations "somewhat."

In spite of the statistically significant study results and encouraging patient experiences, which provide valuable insights into the effectiveness of Prolotherapy for the greater population, this clinical pilot study has several limitations. The small sample size acceptably supports efficacy, action and safety of Prolotherapy for upper and lower cervical spine instability, but the absence of controls may not definitively support the treatment's effectiveness and therapeutic claims. Additional disadvantages relate to the uncertain effect that the injection agents (dextrose, sarapin, PRP, manganese, $\mathrm{Na}$ Morrhuate, polidocanol) may have on the treatment outcome. It may also be probable that some patient improvements may have been spontaneous; however, most patients experienced chronic neck pain for an average of 12 months prior to first Prolotherapy treatment, and time dependence did not play a role in symptom relief, which for 8 patients occurred at 2 to 6 months of treatment. As such, this preliminary data suggest that much of the gain observed may be directly related to treatment. Additional limitations concern the reliance on post-hoc questionnaires and paucity of meaningful interpretations and true event rates due to small number of participants. Nevertheless, the percentage of daily overall sustained improvement attests to moderate objective validation of patient benefit, and the marked frequency of complete post-treatment relief from high baseline values suggests that post-hoc outcome interpretations are not major confounding factors.

Ultimately, considering the statistically significant percentage of total improvements, and the fact that all but 1 study subject expressed overall satisfaction, the study's hypothesis- that Prolotherapy is a viable treatment option for CCSI- has been validated. Stiffness, range of motion, activities of daily living and athletic ability, as well as pain level, are critical factors affecting patients with cervical spine instability. Based on our study results, it is apparent that proliferative injection therapy directly addresses these quality of life issues, and the improvements are objective. On account of research protocols, our study parameters were strict for every patient; however, in a regular private clinic setting, Prolotherapy solution strength and variety may be modified, treatment durations are more flexible, and additional measures are taken to continuously ensure even greater improved outcomes.

Hypertonic dextrose Prolotherapy benefits lie in directly acting on lesions by eliciting vital inflammatory responses like fibroblast and platelet activation, as well as stimulation of cell replication and angiogenesis, which trigger a wide array of regenerative cellular processes. Considering the uncertain efficacy of current conservative treatments, as well as risks, failure rate and expenses associated with suboptimal invasive interventions, proliferative therapy may serve as a viable adjunct to conservative management, and more pivotal research protocols are merited to corroborate on the manifold preventive and regenerative benefits, observed in this study.

\subsection{Conclusion}

Biological models have demonstrated that injuries to the osseous or soft tissues of a joint predispose it to premature, painful, degenerative changes. Particularly, a poorly functioning 3-joint complex of the C-spine (disk and two facet joints) may lead to inter-segmental laxity or instability, with possible facet mediated chronic neck pain. Epidemiological studies, crash testing, and anatomical data all corroborate the fact that cervical facet joints are richly innervated, heal poorly on account of inadequate blood supply, and are prone to injury during even low vehicular impact. A valuable diagnostic tool includes digital motion radiography (video fluoroscopy) to assess painful hypermobility and instability due to post-traumatic and degenerative pathology of capsular and axial ligaments.

Patients with chronic neck pain may go through numerous treatments such as chiropractic, physical therapy and more invasive procedures to relieve pain, whereas more targeted interventions to manage instability and cervical facet joint pain are warranted. The current scientific research relevant to the use of Prolotherapy for clinical cervical spine instability and chronic neck pain provides preliminary evidence supporting the use of hypertonic dextrose injectants in repairing joint laxity, hypermobility and corollary hallmark complaints like neck pain, headache/migraine,, crepitation, dizziness, tinnitus, and vertigo. On the basis of the scarcity of randomized, controlled studies investigating the clinical efficacy of Prolotherapy for cervical musculoskeletal conditions, therapeutic efficacy remains inconclusive, though statistically significant improvements consistently observed in literature reviews and pilot studies provides a justification for future investigations. The substantial gains in pain relief and functionality and lack of adverse effects in the greater majority of our study participants suggest that the procedure is potentially efficacious, comprehensive, exhibits a high safety record, and cost-effective. The effective use of limited resources minimalized factors confining study outcomes, and it is hoped that the statistically significant results can guide future clinical and translational research of Prolotherapy for clinical cervical spine instability.

*Creep: Time dependent elongation of a tissue when subjected to a constant stress

\section{Authors' Contributions}

RAH conceptualized the study and executed it with the assistance of DS and SS. KG contributed to data interpretation and wrote the manuscript.

\section{Acknowledgment}

No other contributors. Karina Gordin (third author/corresponding author) provided the medical writing services on behalf of Caring Medical and Rehabilitation Services. Karina Gordin takes public responsibility for the research, and funding is directly sourced from primary 
researcher Ross Hauser, MD.

\section{References}

[1] White A, Panjabi MM: Clinical Biomechanics of the Spine. Philadelphia: J.B. Lippincott Company; 1978.

[2] Kim CW, Perry A, Garfin SR: Spinal instability: the orthopedic approach. Semin Musculoskelet Radiol 2005, 9(1):77-87.

[3] Dupuis PR, Yong-Hing K, Cassidy JD, Kirkaldy-Willis WH: Radiologic diagnosis of degenerative lumbar spinal instability. Spine 1985, 10(3):262-276.

[4] Lowery DW, Wald MM, Browne BJ, Tigges S, Hoffman JR, Mower WR, NEXUS Group. Epidemiology of cervical spine injury victims. Ann Emerg Med 2001, 38(1):12-16.

[5] Desjardins G: Injuries to the cervical spine [http://www.trauma.org/archive/anaesthesia/cspineanaes.html]

[6] Hoy DG, Protani M, De R, Buchbinder R: The epidemiology of neck pain. Best Prac Res Clin Rheumatol 2010, 24(6):78392.

[7] Barnsley L, Lord S, Bogduk N: Whiplash injury. Pain 1994, 58(3):283-307.

[8] Freeman MD, Croft AC, Rossignol AM, Weaver DS, Reiser M: A review and methodologic critique of the literature refuting whiplash syndrome. Spine 1999, 24(1):86-96.

[9] Panjabi MM, Pearson AM, Ito S, Ivancic PC, Gimenez SE, Tominaga Y: Cervical spine ligament injury during simulated frontal impact. Spine 2004, 29(21):2395-2403.

[10] Siegmund GP, Myers BS, Davis MB, Bohnet HF, Winkelstein BA: Mechanical evidence of cervical facet capsule injury during whiplash: a cadaveric study using combined shear, compression, and extension loading. Spine 2001, 26(19):2095101.

[11] Tominaga $\mathrm{Y}, \mathrm{Ndu} \mathrm{AB}$, Coe MP, Valenson AJ, Ivancic PC, Ito S, Rubin W, Panjabi MM: Neck ligament strength is decreased following whiplash trauma. BMC Musculoskelet Disord 2006, $7: 103$

[12] Foreman SM, Croft AC: Whiplash injuries: the cervical acceleration/deceleration syndrome. Philadelphia: Lippincott Williams \& Wilkins; 2002.

[13] White AA, III, Panjabi MM: Clinical Biomechanics of the Spine. Philadelphia, PA: J.B. Lippincott Company; 1990.

[14] Dickerman RD, Mittler MA, Warshaw C, Epstein JA: Spinal cord injury in a 14-year-old male secondary to cervical hyperflexion with exercise. Spinal Cord 2006, 44(3):192-195.

[15] Benzel E: The Cervical Spine. 5 ed. Philadelphia PA: Lippincot, Williams and Wilkins; 2012.

[16] Volle, E: Functional magnetic resonance imaging- Video diagnosis of soft tissue trauma to the craniocervical joints and ligaments. Int Tinnitus J 2000, 6(2): 134-139.

[17] Saldinger P,Dvorak J, Rahn BA, Perren SM: Histology of alar and transverse ligaments. Spine 1990, 15:257-261.
[18] Dvorak, Scheider E, Saldinger PF, Rahn B: Biomechanics of the craniocervical region: the alar and transverse ligaments. J Orthop Res 1988, 6:452-461.

[19] Schafer RC: Chiropractic Management of Sports and Recreational Injuries. 2 ed. Philadephia: Williams \& Wilkins; 1986.

[20] Dvorak J, Panjabi MM: Functional anatomy of the alar ligaments. Spine1987, 12(2):183-189.

[21] Hulse, M: Die Cervicalen Gleichgewichtsstorungen. Heidelberg: Springer-Verlag; 1983.

[22] Dvorak J, Dvorak V, Drobny T: Manual Medicine: Diagnostics. Stuttgart: Thieme Publishers; 1984.

[23] Darnell MW: A proposed chronology of events for forward head posture. J craniomandibular pract 1983, 1(4):49-54.

[24] Paris SV: Course Notes: The Spine Evaluation and Treatment of Spinal Dysfunction. Course notes: 1978 and 1981.

[25] Rocabado M: Physical Therapy and Dentistry I and II. Course notes, 1979 and 1981.

[26] Jackson R: The Cervical Syndrome. Springfield: Charles C. Thomas Publisher; 1977.

[27] Kirkaldy-Willis WH, Farfan HF: Instability of the lumbar spine. Clin Orthop 1982, (165):110-123.

[28] Chen B, Fellenberg J, Wang H, Carstens C, Richter W: Occurrence and regional distribution of apoptosis in scoliotic discs. Spine 2005, 30(5):519-524.

[29] Wang YJ, Shi Q, Lu WW, Cheung KC, Darowish M, Li TF, Dong YF, Zhou CJ, Zhou Q, Hu ZJ, Liu M, Bian Q, Li CG, Luk KD, Leong JC: Cervical intervertebral disc degeneration induced by unbalanced dynamic and static forces: a novel In Vivo rat model. Spine 2006, 31(14):1532-1538.

[30] Schafer RC: Clinical Biomechanics: Musculoskeletal Actions and Reactions. 2 ed. Philadelphia: Williams \& Wilkins;1983.

[31] Nicholl EA: Fractures of the dorso-lumbar spine. J Bone Joint Surg Br 1949, 31B(3): 376-394.

[32] Pope MH, Panjabi MM: Biomechanical definitions of spinal instability. Spine 1985, 10(3):255-256.

[33] Rocabado M: The importance of soft tissue mechanics in stability and instability of the cervical spine: a functional diagnosis for treatment planning. J Craniomandibular Pract $1987,5(20): 130-138$

[34] Ebraheim NA, Xu R, Ahmad M, Heck B, Yeasting RA: The effect of anterior translation of the vertebra on the canal size in the lower cervical spine: a computer-assisted anatomic study. J Spinal Disord 1997, 10(2):162-166.

[35] Panjabi MM: The stabilizing system of the spine. Part II. Neutral zone and instability hypothesis. J Spinal Disord 1992, 5(4):390-397.

[36] Kritjansson E, Leivseth G, Brinckmann P, Frobin W: Increased sagittal plane segmental motion in the lower cervical spine in women with chronic whiplash associated disorders, grades I-II: a case control study using a new measurement protocol. Spine 2003,28(19):2215-2221. 
[37] Cook C, Brismee JM, Fleming R, Sizer PS: Identifiers suggestive of clinical cervical spine instability: a Delphi study of physical therapists. Phys Ther 2005, 85:895-906.

[38] Vandemark RM: Radiology of the cervical spine in trauma patients: practice pitfalls and recommendations for improving efficiency and communication. Am J Roentgenol 1990, 155(3):465-72.

[39] Gatterman M: Foundations of Chiropractic, 1st ed. St. Louis: Mosby/Elsevier; 1995.

[40] Hino H, Abumi K, Kanayama M, Kaneda K: Dynamic motion analysis of normal and unstable cervical spines using cineradiography. An in vivo study. Spine1999, 24(2):163-168.

[41] Binkley J, Finch E, Hall J, Black T, Gowland C: Diagnostic classification of patients with low back pain: Report on a survey of physical therapy experts. PhysTher 1993, 73(3):138-155.

[42] Baumgarten M, Mouradian W, Boger D, Watkins R: Computed axial tomography in C1-C2 trauma. Spine 1985, 10:187-192.

[43] Ono K, Yonenobu K, Fuji T, Okada K: Atlantoaxial rotary fixation: Radiographic study of its mechanism. Spine 1985, 10(7):602-608.

[44] Hutting N, Scholten-Peeters GG, Vijverman V, Keesenberg MD, Verhagen AP: Diagnostic accuracy of upper cervical spine instability tests: a systematic review. Phys Ther 2013,93(12): 1686-1695.

[45] Jull G: Whiplash, Headache and Neck Pain. N.p.: Elsevier Limited; 2008.

[46] Volle E: Diagnostische Methoden bei Verletzungen am kraniozervikalen Übergang. In: Moskopp D, Wassmann $\mathrm{H}$, editors. Neurochirurgie. Handbuch für die Weiterbildung und interdisziplinäres Nachschlagewerk. New York: Schattauer Verlag; 2004.

[47] Johansson BH: Whiplash injuries can be visible by functional magnetic resonance imaging. Pain Res Manag 2006, 11(3):197-199.

[48] Dvorak J: Musculoskeletal Manual Medicine. Stuttgart, Germany: Georg Thieme Verlag; 2008.

[49] Antinnes JA, Dvorák J, Hayek J, Panjabi MM, Grob D: The value of functional computed tomography soft-tissue injury in the upper cervical spine. Eur Spine J 1994,3(2):98-101.

[50] Dvorak J, Panjabi MM, Novotny JE, Antinnes JA: In vivo flexion extension of the normal cervical spine. J Orthop Res 1991, 9:828-834.

[51] Dvorak J, Penning L, Hayek J, Panjabi MM, Grob D, Zehnder R: Functional diagnostics of the cervical spine using computer tomography. Neuroradiology 1988, 30(2):132-37.

[52] Lord SM, Barnsley L, Wallis BJ, Bogduk N: Chronic cervical zygapophysial joint paint after whiplash: a placebo controlled prevalence study. Spine 1996, 21(15):1737-1744.

[53] Manchikanti L, Boswell MV, Singh V, Pampati V, Damron KS, Beyer CD: Prevalence of facet joint pain in chronic spinal pain of cervical, thoracic and lumbar regions. BMC Musculoskelet Disord 2004, 5:15.
[54] Bogduk N: The clinical anatomy of the cervical dorsal rami. Spine 1982, 7:35-45.

[55] Dwyer A, Aprill C, Bogduk N. Cervical zygapophyseal joint pain patterns. I: a study in normal volunteers. Spine 1990, 6:453-457

[56] Manchikanti L, Singh V, Rivera J, Pampati V: Prevalence of cervical facet joint pain in chronic neck pain. Pain Physician 2002, 5(3):243-249.

[57] Schafer RC: Clinical Biomechanics: Musculoskeletal Actions and Reactions. 2 ed. Philadelphia: Williams \& Wilkins; 1983.

[58] Quinn KP, Bauman JA, Crosby ND, Winkelstein BA: Anomalous fiber realignment during tensile loading of the rat facet capsular ligament identifies mechanically induced damage and physiological dysfunction. J. Biomech 2010, 43(10):1870-1875.

[59] Jaumard NV, Welch WC, Winkelstein BA: Spinal facet joint biomechanics and mechanotransduction in normal, injury and degenerative conditions. J Biomech Eng 2011, 133(7):071010.

[60] Fujiwara A, Lim TH, An HS, Tanaka N, Jeon CH, Andersson GB, Haughton VM: The effect of disc degeneration and facet joint osteoarthritis on the segmental flexibility of the lumbar spine. Spine 2000, 25(23):3036-3044.

[61] Provenzano PP, Alejandro-Osorio AL, Valhmu WB, Jensen KT, Vanderby R Jr: Intrinsic fibroblast-mediated remodeling of damaged collagenous matrices in vivo. Matrix Biol 2005, 23(8):543-555.

[62] Ramage L, Nuki G, Salter DM: Signaling cascades in mechanotransduction: cell-matrix interactions and mechanical loading. Scand J Med Sci Sports 2009, 19(4):457-469.

[63] Giles LG, Harvey AR: Immunohistochemical demonstration of nociceptors in the capsule and synovial folds of human zygapophyseal joints. Br J of Rheumatol 1987,26(5):362-364.

[64] Cramer G, Darby SA: Clinical Anatomy of the Spine, Spinal Cord and ANS. 3d ed. St. Louis, MO: Mosby/Elsevier; 1995.

[65] Bogduk N, Lord SM: Cervical zygapophysial joint pain. Neurosurg Quart 1998, 8:107-117.

[66] Pearson AM, Invancic PC, Panjabi MM: Facet joint kinematics and injury mechanisms during simulated whiplash. Spine 2004, 29(4):390-397.

[67] Winkelstein BA, McLendon RE, Barbir A, Myers BS: An anatomical investigation of the human cervical facet capsule, quantifying muscle insertion area. J Anat 2001, 198(pt 4):455461.

[68] Winkelstein BA, Nightingale RW, Richardson WJ, Myers BS: Cervical facet joint mechanics: its application to whiplash injury. Proceedings of the 43 Stapp Car Crash Conference. pp243-252.

[69] Stemper BD, Yoganandan N, Pinter FA: Effects of abnormal posture on capsular ligament elongations in a computational model subjected to whiplash loading. J Biomech 2005, 38(6):1313-1323.

[70] Lu Y, Chen C, Kallakuri S, Patwardhan A, Cavanaugh JM: Neural response of cervical facet joint capsule to stretch: a 
study of whiplash pain mechanism. Stapp Car Crash J 2005,49:49-65.

[71] Winkelstein BA, Nightingale RW, Richardson WJ, Myers BS: The cervical facet capsule and its role in whiplash injury: a biomechanical investigation. Spine 2000, 25(10): 1238-1246.

[72] Iatridis JC, MaClean JJ, Ryan DA: Mechanical damage to the intervertebral disc annulus fibrosus subjected to tensile loading. J Biomech 2005, 38(3): 557-565.

[73] Foster CA, Jabbour P: Barré-Lieou syndrome and the problem of the obsolete eponym. J Laryngol Otol 2007, 121(7):680683 .

[74] McIntosh J: Chedoke-McMaster Hospital's Musculoskeletal physiotherapy program: Internal Report. Hamilton, Ontario, Canada: Physiotherapy Departmental Report; 1992.

[75] Borghouts JA, Koes BW, Vondeling H, Bouter LM: Cost of illness in neck pain in the Netherlands in 1996. Pain 1999,80(3):629-636.

[76] Spitzer WO: Scientific approach to the assessment and management of activity-related spinal disorders: a monograph for clinicians: Report of the Quebec Task Force. Spine 1987, 12:S1-59.

[77] Borghouts JA, Koes BW, Bouter LM: The clinical course and prognostic factors of nonspecific neck pain: a systematic review. Pain 1998, 77(1):1-13.

[78] Rubinstein SM, Terwee CB, Assendelft WJ, de Boer MR, van Tulder MW: Spinal manipulative therapy for acute low-back pain. Cochrane Database Syst Rev. 2012 Sep 12;9:CD008880.

[79] Di Fabio RP: Efficacy of manual therapy. Phys Ther 1992, 72:853-864.

[80] Aker PD, Gross AR, Goldsmith CH, Peloso P: Conservative management of mechanical neck pain: systematic overview and meta-analysis. BMJ 1996, 313(7068):1291-6.

[81] Bronfort G: Efficacy of spinal manipulation and mobilization for low back and neck pain: a systematic review and best evidence synthesis. PhD thesis. Amsterdam, Netherlands: Thesis Publishers; 1997.

[82] Hurwitz EL, Aker PD, Adams AH, Meeker WC, Shekelle PG: Manipulation and mobilization of the cervical spine: A systematic review of literature. Spine 1996, 21(15):1746-1760.

[83] Nilsson N, Christensen HW, Hartvigsen J: Lasting changes in passive range of motion after spinal manipulation: a randomized, blind, controlled trial. JMPT 1996, 19(3): 165168 .

[84] Gross AR, Kay T, Hondras M, Goldsmith C, Haines T, Peloso $P$ : Manual therapy for mechanical neck disorders: a systematic review. Man Ther 2002, 7(3):131-49.

[85] Peeters GG, Verhagen AP, de Bie RA, Oostendorp RA: The efficacy of conservative treatments in patients with whiplash injury: a systematic review of clinical trials. Spine 2001, 26(4):E64-E73.

[86] Norris JW, Beletsky V, Nadareishvili ZG: Sudden neck movement and cervical artery dissection. The Canadian Stroke Consortium. CMAJ 2000, 163(1):38-40.
[87] Ernst E: Manipulation of the cervical spine: a systematic review of case reports of serious adverse events, 1995-2001. Med J 2002,176:376-80.

[88] Parenti G, Orlandi G, Bianchi M, Renna M, Martini A, Murri L: Vertebral and carotid artery dissection following chiropractic cervical manipulation. Neurosurg Rev 1999, 22(2-3):127-129.

[89] Mehalic T, Farhat SM: Vertebral artery injury from chiropractic manipulation of the neck. Surg Neurol 1974, 2(2):125-129.

[90] Nall SK: The role of specific manipulation towards alleviating abnormalities in body mechanics and restoration of spinal motion. J Manip Physiol Ther 1982, 5(1):11-15.

[91] Mannen E: The use of cervical radiographic overlays to assess response to manipulation. J Can Chiropr Assoc 1980, 24(3): $108-110$.

[92] Tippets RH, Apfelbaum RI: Anterior fusion with the caspar instrumentation system. Neurosurgery 1988,22(6 pt 1):10081013.

[93] Deyo RA, Gray DT, Kreuter W, Mirza S, Martin BI: United States trends in lumbar fusion surgery for degenerative conditions. Spine 2005,30(12):1441-1445.

[94] Abelson R, Petersen M: An Operation to Ease Back Pain Bolsters the Bottom Line, too. The New York Times, December 31, 2003.

[95] Munro D: The factors that govern the stability of the spine. Paraplegia 1965, 3:219-228.

[96] Brav EA, Miller JA, Bouzard WC: Traumatic dislocation of the cervical spine: army experience and results. J Trauma 1963,3:569-582.

[97] Binder A: Neck pain. Clin Evid (Online). 2008;2008:1103.

[98] Shamji MF, Cook C, Pietrobon R, Tackett S, Brown C, Isaacs RE: Impact of surgical approach on complications and resource utilization of cervical spine fusion: a nationwide perspective to the surgical treatment of diffuse cervical spondylosis. Spine J 2009, 9(1):31-38.

[99] De Graaff R: Congential block vertebrae C2-C3 in patients with cervical myelopathy. Acta Neurochir 1982,61(1-3):111-126.

[100] Bydon M, Xu R, Macki M, De la Garza-Ramos R, Sciubba DM, Wolinsky JP, Witham TF, Gokaslan ZL, Bydon A: Adjacent segment disease after anterior cervical discectomy and fusion in a large series. Neurosurgery 2014, 74(2):139146.

[101] Todd AG: Cervical spine: degenerative conditions. Curr Rev Musculoskelet Med 2011, 4(4): 168-174.

[102] Gruss P, Tannenbaum H: Stress exertion on adjacent levels after ventral ventrical fusion. Arch Orthop Trauma Surg 1983, 101:283-286.

[103] Xu R, Bydon M, Macki M, De la Garza-Ramos R, Sciubba DM, Wolinsky JP, Witham TF, Gokaslan ZL, Bydon A: Adjacent segment disease after anterior cervical discectomy and fusion: clinical outcomes after first repeat surgery versus second repeat surgery. Spine 2014,39(2):120-126. 
[104] James Yue: The Comprehensive Treatment of the Aging Spine: Minimally Invasive and Advanced Techniques. Philadelphia PA: Saunders/Elsevier;2011.

[105] Greene J: Cost-conscious prescribing of nonsteroidal antiinflammatory drugs for adults with arthritis. Arch Internal Med 1992, 152: 1995-2002.

[106] Almekinders LC, Baynes AJ, Bracey LW: An in vivo investigation into the effects of repetitive motion and nonsteroidal anti-inflammatory medical on human tendon fibroblasts. Am J Sports Med 1995,23:119-123.

[107] Kulick MI, Smith S, Hadler K: Oral ibuprofen: evaluation of its effect on peritendinous adhersions and the breaking strength of a tenorrhaphy. J Hand Surg Am 1986,11A:110-119.

[108] Snider R: Essentials of Musculoskeletal Care. Rosemont, IL: American Academy of Orthopaedic Surgeons; 1997.

[109] Truhan AP, Ahmed AR: Corticosteroids: a review with emphasis on complications of prolonged systemic therapy. Ann Allergy 1989,62(5):375-290.

[110] Gogia PP, Brown M, al-Obaidi S: Hydrocortisone and exercise effects on articular cartilage in rats. Arch Phys Med Rehabil 1993, 74(5):463-467.

[111] Ferland M: Necrose localisee due a une injection intratendineuse de glucocorticoide: etude experimentale comparative. Union Med Can. 1972; 101: 1768-1771.

[112] Carayannopoulos A, Borg-Stein J, Sokolof J, Meleger A, Rosenberg D: Prolotherapy vs corticosteroid injections for the treatment of lateral epicondylosis: a randomized, controlled trial. PM R 2011,3(8):706-715.

[113] Jobe FW, Ciccotti MG: Lateral and medial epicondylitis of the elbow. J Am Acad Orthop Surg 1994,2(1):1-8.

[114] Speed CA: Corticosteroid injections in tendon lesions. Br Med J 2001,323(7309):382-386.

[115] Labelle H, Guibert R, Joncas J, Newman N, Fallaha M, Rivard $\mathrm{CH}$ : Lack of scientific evidence for the treatment of LE of the elbow. An attempted meta-analysis. J Bone Joint Surg Br 1992 74(5):646-651

[116] Hirpara KM, Butler JS, Dolan RT, O’Byrne JM, Poynton AR: Nonoperative modalities to treat symptomatic ervical spondylosis. Adv Orthop 2012, 2012: 294857.

[117] Gross AR, Goldsmith C, Hoving JL, Haines T, Peloso P, Aker P: Conservative management of mechanical neck disorders: a systematic review. J Rheumatol 2007,34(5):1083-102.

[118] Persson LC, Carlsson CA, Carlsson JY: Long-lasting cervical radicular pain managed with surgery, hysiotherapy, or a cervical collar. A prospective, randomized study. Spine 1997, 22(7):751-8.

[119] Persson LC, Moritz U, Brandt L, Carlsson CA: Cervical radiculopathy: pain, muscle weakness and sensory loss in patients with cervical radiculopathy treated with surgery, physiotherapy or cervical collar. A prospective, controlled study. Eur Spine J 1997,6(4):256-66.

[120] Matz PG: Does nonoperative management play a role in the treatment of cervical spondylotic myelopathy? Spine J 2006, 6(6 Suppl):175S-181S.
[121] Olson KA, Joder D: Diagnosis and treatment of cervical spine clinical instability. J Orthop Sports Phys Ther 001, 31(4):194206.

[122] Ho KY, Tan KH: Botulinum toxin A for myofascial trigger point injection: a qualitative systematic review. Eur J Pain 2007,11(5):519-27.

[123] Langevin P, Peloso PM, Lowcock J, Nolan M, Weber J, Gross A: Botulinum toxin for subacute/chronic neck ain. Cochrane Database Syst Rev. 2011 Jul 6;(7):CD008626.

[124] Landa J, Kim Y: Outcomes of interlaminar and transforminal spinal injections. Bull NYU Hosp Jt Dis 012,70(1):6-10.

[125] Boswell MV, Trescot AM, Datta S, Schultz DM, Hansen HC, Abdi S, Sehgal N, Shah RV, Singh V, Benyamin RM, Patel VB, Buenaventura RM, Colson JD, Cordner HJ, Epter RS, Jasper JF, Dunbar EE, Atluri SL, Bowman RC, Deer TR, Swicegood JR, Staats PS, Smith HS, Burton AW, Kloth DS, Giordano J, Manchikanti L: Interventional techniques: evidence-based practice guidelines in the management of chronic spinal pain. Pain Physician 2007,10(1):7-111.

[126] Johnson M: Prolotherapy and connective tissue damage syndrome. J Prolotherapy 2009,1(1):45-53.

[127] Hooper RA, Frizzell JB, Faris P: Case series on chronic whiplash related neck pain treated with intraarticular zygapophysial joint regeneration injection therapy. Pain Physician 2007,10(2):313-318.

[128] Reeves, KD, Hassanein K: Randomized prospective double blind placebo controlled study of dextrose prolotherapy for knee osteoarthritis with or without (ACL) laxity. Altern Ther Health Med 2000,6(2):68-74, 77-80.

[129] Ongley MJ, Klein RG, Dorman TA, Eek BC, Hubert LJ: A new approach to the treatment of chronic low back pain. Lancet 1987,2(8551):143-146.

[130] Bordeau Y: Five year follow up on sclerotherapy/prolotherapy for low back pain. Manual Medicine 1988,3:155-157.

[131] Klein Rg, Eek BC, DeLong WB, Mooney V: A randomized double blind trial of dextrose glycerine phenol injections for chronic low back pain. J Spinal Disord 1993,6(1):23-33.

[132] Kayfetz DO: Occipito-cervical (whiplash) injuries treated Prolotherapy. Med Trial Tech Q 1963,9:9-29.

[133] Hackett G: Prolotherapy in Whiplash and Low back pain. Postgrad Med 1960, 27:214-219.

[134] Hooper RA: Case series on chronic whiplash related neck pain treated with intraarticular zygapophysial joint regeneration injection therapy. Pain Physician 2007, 10:313-318.

[135] Hooper RA, Ding M: Retrospective case series on patients with chronic spinal pain treated with dextrose Prolotherapy. J Altern Complement Med 2004,10(4):670-4.

[136] Centeno CJ, Elliott J, Elkins WL, Freeman M: Fluoroscopically guided cervical Prolotherapy for instability with blinded pre and post radiographic reading. Pain Physician 2005,8(1):67-72.

[137] Hauser R, Hauser M: Dextrose Prolotherapy for unresolved neck pain. Practical Pain Management 2007:56-69. 
[138] Kayfetz, DO, Blumenthal LS, Hackett GS, Hemwall GA, Neff FE: Whiplash injury and other ligamentous headache- its management with Prolotherapy. Headache 1963,3:21-28.

[139] Hackett GS, Huang TC, Raftery A: Prolotherapy for headache. Pain in the head and neck, and neuritis. Headache 1962,2(1):20-28.

[140] Dagenais S, Haldeman S, Wooley JR: Intraligamentous injection of sclerosing solutions (Prolotherapy) for spinal pain: a critical review of the literature. Spine J 2005,5(3):310-328.
[141] Dorman T: Whiplash injuries: treatment with prolotherapy and a new hypothesis. J Orthop Med 1999;21(1):13-21.

[142] Hooper A, Yelland M: Prospective case series of litigants and non-litigants with chronic spinal pain treated with dextrose Prolotherapy. Int Musculoskeletal Med 2011,33(1):15-20.

[143] Rabago D, Best TM, Beamsley M, Patterson J: A systematic review of Prolotherapy for chronic musculoskeletal pain. Clin J Sport Med 2005, 15(5): E376. 